\title{
Bio-Stoning of Denim- An Environmental-Friendly Approach
}

\author{
Bipin J Agrawal* \\ Department of Textile Chemistry, The Maharaja Sayajirao University of Baroda, India
}

Submission: April 18, 2017; Published: April 26, 2017

"Corresponding author: Bipin J Agrawal, Associate Professor, Department of Textile Chemistry, Faculty of Technology \& Engineering, The Maharaja Sayajirao University of Baroda, Vadodara-390 001, Gujarat, India, Tel: 91 9924297828; Email: drbipinagrawal_59@yahoo.com

\begin{abstract}
Enzymes have been used in textile processing since the early part of the last century to remove starch-based sizing, but only in the past two decades serious attention has been given to using enzymes for a wide range of textile applications. Jeans, manufactured from denim, are one of the world's most popular clothing items. The "stonewash look" has been traditionally achieved by locally removing the indigo dye using a process in which pumice stone is added to the washing drum to abrade the garment. This traditional 'stone-washed' finish on denim fabric virtually damaged the machinery and caused pollution in waste water. The concept of biotechnology can be utilized to facilitate the removal of indigo dye from the yarn surface. The new environmental-friendly process, termed as bio-stoning, uses enzymes to wash/bio-stone denim, producing distressed appearance, without harming the machinery or the environment. The bio-stoning of denims has resulted in cost saving and improved quality and is used by many denim manufacturers.
\end{abstract}

Keywords: Denim; Bio-stoning; Pumice stone; Stone wash; Indigo

\section{Opinion}

Denim jeans, dyed with natural or synthetic indigo, are the most popular garments worn by individuals of all ages and approximately one billion pairs of jeans are produced per annum. Traditionally, denim has been woven with cotton in a warp face twill weave, in which the warp is blue whereas the weft is white. Dyeing is usually performed with pure indigo, or indigo combined with a sulfur dye to decrease the costs caused by the more expensive indigo dye. Indigo dye is popular because it washes down to clear bright blue shades without staining of the white weft yarns.

Most denim jeans or other denim garments are subjected to a wash treatment to give them a slightly worn look. In the traditional stonewashing process, the blue denim is faded by the abrasive action of light-weight pumice stones on the garment surface, which removes some of the dye. Stonewashing added a new dimension to denim garments in the late 1970s: the process facilitated artificial ageing of denim garments which imparted a fashionably aged appearance. As the name 'stonewashing' suggests, the blue jeans were washed with pumice stones to accomplish a faded look. However, the usage of pumice stones possess many limitations, such as damage of the machine parts, blocking of the drainage system, difficulty in removing the residues of the pumice-stones, and requirement of large amount of stone for even small batches. Moreover, too much abrasion may also damage the fabric, particularly hems, seams and waistbands. So the alternative methods for stonewashing were developed [1-3].

Cellulase enzymes were introduced in the 1980 s as a denimwashing assistant to achieve a faded and abraded look analogous to that provided by pumice stones. Cellulase accelerates the abrasion by loosening the indigo dye on the denim in a process known as 'bio stone washing'. The use of enzymes allows the denim garment washing procedure to be carried out under mild conditions in the absence of pumice stones and harsh chemical agents. As a result of bio-stoning process, a more uniform aged look for denim garment may be achieved. Different visual effects may also be induced on fabrics. A small dose of enzyme can replace several kilograms of pumice stones. Biostone washing has opened up new opportunities in denim finishing by increasing the variety of finishes available [4-7]. For example, it is now feasible to fade denim to a greater degree without any possibility of damaging the garment (Figure 1). Productivity can also be increased because laundry machines contain fewer stones or no stones and more garments. The use of less pumice stone results in less damage to garment and machine, and 
less pumice dust in the laundry environment. There is also no sediment in the wastewater, which can otherwise block drains.

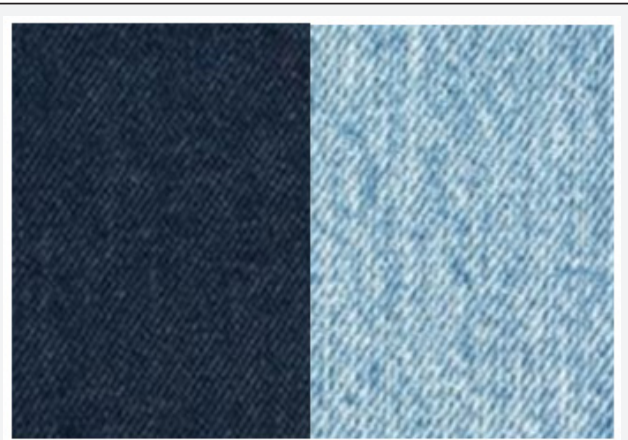

Figure 1: (a) Original (Raw) Indigo dyed denim (b) Bio-stone washed denim.

A range of cellulase for denim finishing, each with its own distinctive properties, is available in the market. These can be used either alone or in combination with pumice stones in order to obtain a specific look. An ideal biostone wash enzyme would possess high abrasive activity (the ability to remove indigo from denim) as well as low back staining with lower fabric strength loss.

Cellulases have been used for the past twenty years and it is estimated that approximately $80 \%$ of denim garments are processed in this way. Cellulases are enzymes that are specific for the hydrolysis of the beta-1, 4 glucose linkage of cellulose. The reaction mechanism of the naturally occurring cellulase enzymes on cellulose is very complicated and several different enzymes endoglucanases, cellobiohydrolases and beta-glucosidases are synergistically involved in the chain of reactions needed to break down cellulose into glucose. Both neutral cellulases (acting at $\mathrm{pH}$ 6-8) and acid cellulases (acting at $\mathrm{pH} 4-6$ ) are used for the abrasion of denim [8-10].

The first commercial cellulase enzyme introduced to market was derived from the Trichoderma family, a fungus with the longest history of cellulase research. The second phase in the development of cellulase was the introduction of products based on another fungus called Humicola insolens. These cellulases soon became known as the neutral cellulases as they could work in a more neutral $\mathrm{pH}$ environment. A special feature of the neutral cellulases is their ability to provide the stonewashed look with minimal indigo re-deposition during the treatment. Thus, the jeans and other denim garments would have a higher contrast between white and blue yarns, and the inside pockets as well as the leather labels would not be stained with indigo. However, the reaction time of this enzyme is slow and its use requires a longer processing time.

The mode of action of cellulases can be explained as followsdenim garments are dyed with indigo, a dye that penetrates only the surface of the yarn, leaving the centre light in colour. Cellulase enzymes are natural proteins which are used in denim garment processing to get stone wash look on to the denim garments without using stones or by reducing the use of pumice stone. Cellulase attacks primarily on the surface of the cellulose fiber; the cellulase molecule binds to an exposed fibril (bundles of fibrils make up a fiber) on the surface of the yarn and hydrolyzes it, leaving the interior of the fiber as it is, by removing the indigo present in the surface layer of fiber. When the cellulases partly hydrolyze the surface of the fiber, the blue indigo is released, aided by mechanical action, from the surface and light areas become visible, as desired as visualized from Figure 2 .

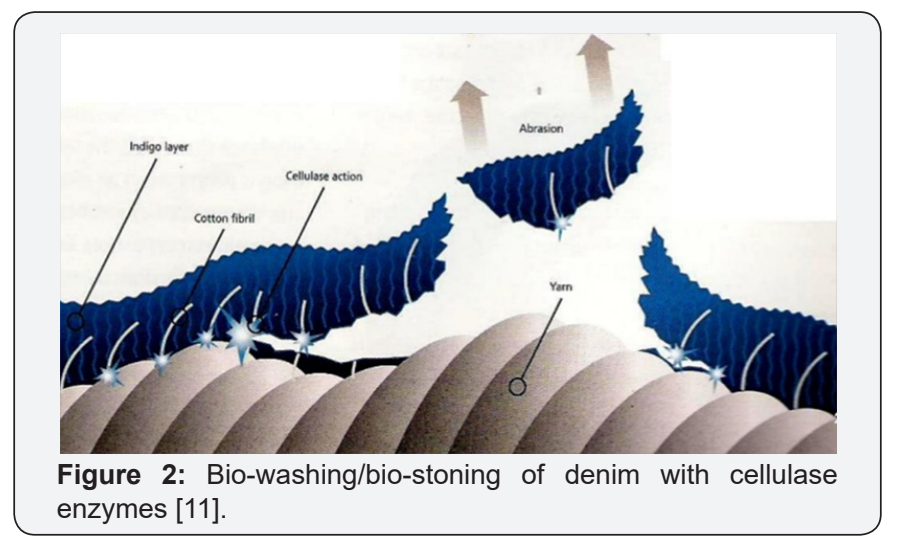

One of the problems associated with the denim bio-stoning is back-staining. Back-staining is defined as the re-deposition of released indigo onto the garments. This effect is quite important in denim finishing. The washing out of the indigo dye from the blue yarn of the denim substrate may stain the white yarn due to the enzymatic treatment. Most consumers prefer high quality jeans with low back-staining. Application research in this area is focused on preventing or enhancing back-staining depending on the style required. Back-staining at low $\mathrm{pH}$ values (pH 4-6) is relatively high, whereas it is significantly lower in the neutral $\mathrm{pH}$ range. Neutral cellulases are therefore. often used when the objective is minimal back-staining.

Recently, to achieve specific applications and to keep pace with the latest fashion inclinations of the denim industry, research and development activities have been focused to customize on a new generation of cellulase enzymes whose configuration has been reformed through genetic engineering to deliver higher abrasion contrast, reduced back staining, improved fabricstrength retention and extended operating $\mathrm{pH}$ and temperature ranges. The development of contemporary biotechnology brought new implements for scientists to craftnovel, improved cellulase products for textile applications.

The various cellulases available as the DeniMax $₫$ product range, developed by Novozymes, for modifying the surface of denim give fashion designers a pallet of potentials for creating novel shades and finishes. Bleaching or fading of the blue indigo color can also be attained by use of another enzyme product (DeniLite ${ }^{\circledR}$ ) based on a laccase and a mediator compound. This 
system together with dioxygen from the air oxidizes and thereby bleaches indigo, creating a faded look. This bleaching effect was earlier only obtainable using harsh chlorine-based bleach. The combination of new looks, lower costs, shorter treatment times and less solid waste has made abrasion and bleaching with enzymes the most widely used fading processes today [12].

Novozymes (earlier Novo Nordisk) has also patented a method in which a stone-washing effect of denim was obtained by using xyloglucan polymer prior to dyeing and afterwards creating the abraded or worn look by enzymatic degradation of the polymer using xylo-glucanase. The xylo-glucanase is not able to hydrolyze the cellulosic fabric, and therefore no strength loss is resulted [12].

Valumax A 838 is a high-performance, direct-to-use cellulase enzyme for the abrasion of denim (bio-stonewashing). This product allows new shades and finishes to be created easily and cost effectively, in an environmentally-friendly way. The outstanding features of this innovative cellulase enzyme, developed by Novozymes, are high color contrast finish, low degree of indigo back staining, optimum strength retention, high degree of reproducibility and reliability, maximized fabric strength retention, improved wash look or creation of new looks, easy handling and cost effectiveness [12].

\section{References}

1. Byrne C, Rigby D (1995) Biotechnology in textiles. Proceedings of the Textile Institute's Dyeing and Finishing Group Conference, Nottingham, England.
2. Shelke V (2001) Enzymatic decolourization of denims: A novel approach. Colourage 48(1): 25.

3. Doshi R, Shelke V (2001) Enzymes in the Textile Industry-An Environment-Friendly Approach. Indian Journal of Fibres \& Textile Research 26(1-2): 202-206.

4. Jenkins RO (2003) Textile Processing with Enzymes, Cavaco-Paulo A Gübitz GM (Eds.), Woodhead Publishing Ltd. CRC Press, Boca Raton, USA.

5. Muthu, MM, Ganesh PJ (2004) Application of bio-technology in textiles. Colourage 52(10): 41-48.

6. Schmidt M (1995) Enzymes in textile Finishing. Melliand International 2: $116-118$

7. Shirish Kumar GVN (2007) Scope of bio-technology in textiles. Journal of the Textile Association (3-4): 263-266.

8. Kathiervelu SS (2002) Textile Trends 45(12): 33-36.

9. http://www.fibre2fashion.com/industry-article/50/4990/denimfinishing3.asp

10. Schmitt B, Prasad AK (1998) Update of Indigo denim washing: Efficient way of washing denim garment with bio routes. Colourage45(10): 2024.

11. https://www.slideshare.net/abiramprince/effect-of-physicalproperties-of-cotton-on-enzyme-concentration

12. Novozymes report (2006). 